Research paper

\title{
Regulating Cannabis Social Clubs: A comparative analysis of legal and self-regulatory practices in Spain, Belgium and Uruguay
}

\author{
Tom Decorte, ${ }^{\mathrm{a}, *}$, Mafalda Pardal ${ }^{\mathrm{a}}$, Rosario Queirolo ${ }^{\mathrm{b}}$, Maria Fernanda Boidic, \\ Constanza Sánchez Avilés ${ }^{\mathrm{d}}$, Òscar Parés Franquero ${ }^{\mathrm{d}}$ \\ a Institute for Social Drug Research (ISD), Ghent University, Belgium \\ ${ }^{\mathrm{b}}$ Department of Social and Political Sciences, Universidad Católica del Uruguay, Uruguay \\ ' Insights Research and Consulting \\ d ICEERS Foundation, Barcelona, Spain
}

\section{A R T I C L E I N F O}

\section{Article history:}

Received 20 June 2016

Received in revised form 22 December 2016

Accepted 31 December 2016

Available online $\mathrm{xxx}$

\section{Keywords:}

Cannabis

Cannabis Social Clubs

Supply

Regulatory model

Cannabis policy

\begin{abstract}
A B S T R A C T
Background: Cannabis Social Clubs (CSCs) are a model of non-profit production and distribution of cannabis among a closed circuit of adult cannabis users. CSCs are now operating in several countries around the world, albeit under very different legal regimes and in different socio-political contexts. Aim: In this paper we describe and compare the legal framework and the self-regulatory practices of Cannabis Social Clubs in three countries (Spain, Belgium, and Uruguay). The objective of our comparative analysis is to investigate how CSCs operate in each of these countries. To foster discussions about how one might regulate CSCs to promote public health objectives, we conclude this paper with a discussion on the balance between adequate governmental control and self-regulatory competences of CSCs.

Methods: The data used for this analysis stem from independently conducted local studies by the authors in their countries. Although the particular designs of the studies differ, the data in all three countries was collected through similar data collection methods: analysis of (legal and other documents), field visits to the clubs, interviews with staff members, media content analysis.

Findings: We identified a number of similarities and differences among the CSCs' practices in the three countries. Formal registration as non-profit association seems to be a common standard among CSCs. We found nevertheless great variation in terms of the size of these organisations. Generally, only adult nationals and/or residents are able to join the CSCs, upon the payment of a membership fee. While production seems to be guided by consumption estimates of the members (Spain and Belgium) or by the legal framework (Uruguay), the thresholds applied by the clubs vary significantly across countries. Quality control practices remain an issue in the three settings studied here. The CSCs have developed different arrangements with regards to the distribution of cannabis to their members.

Conclusions: By uncovering the current practices of CSCs in three key settings, this paper contributes to the understanding of the model, which has to some extent been shaped by the self-regulatory efforts of those involved on the ground. We suggest that some of these self-regulatory practices could be accommodated in future regulation in this area, while other aspects of the functioning of the CSCs may require more formal regulation and monitoring. Decisions on this model should also take into account the local context where the clubs have emerged. Finally, the integration of medical supply within this model warrants further attention.
\end{abstract}

(c) 2017 Elsevier B.V. All rights reserved.

\section{Introduction}

While the debate on cannabis policy has often been polarised around either total prohibition or legalisation, such positions tend to draw on an oversimplification of what 'legalisation' and

\footnotetext{
* Corresponding author.

E-mail address: tom.decorte@ugent.be (T. Decorte).
}

'prohibition' entails and do not capture well the range of options available (Caulkins et al., 2015a, 2015b; MacCoun, Reuter, \& Schelling, 1996; MacCoun \& Reuter, 2011; Transform, 2013). Caulkins et al. (2015a) identified and compared twelve broad supply models, which could be alternatives to the current prohibition regime. They referred to a range of middle ground options, including 'locally controlled retail sales' in line with the so-called Dutch coffee-shop model, which relies on non-enforcement against retail selling and possession (drawing on a 
expediency principle), under certain conditions (Korf, 2011; MacCoun, 2013; MacCoun and Reuter, 2001, 2011; Room, Fischer, Hall, Lenton, \& Reuter, 2010). Domestic cultivation or a 'grow your own' model which allows users to cultivate their own cannabis has also been formally introduced or tolerated in several jurisdictions (MacCoun, 2013; MacCoun and Reuter, 2011). The introduction of a government monopoly with direct control of the supply of cannabis or the allocation of that role to a public authority are other possible avenues - with a view to reduce the involvement of for-profit firms in the market. Other middle ground options may be based on a license-system, granted for instance to a restricted number of for profit-firms.

The focus of this paper is on yet another possible middle ground option: the Cannabis Social Clubs. A Cannabis Social Club (CSC $)^{1}$ is a legally constituted non-profit association of cannabis consumers. Cannabis Social Clubs collectively cultivate cannabis plants for their adult members, to meet their personal needs (Barriuso, 2005, 2011; Room et al., 2010). According to the 'Code of Conduct' of the European Coalition for Just and Effective Drug Policies (ENCOD, 2011), Cannabis Social Clubs are a model initiated by cannabis users, "to prevent cannabis consumers from being involved in illegal activities and assures that certain requirements concerning public health and safety are being fulfilled. Cannabis Social Clubs (CSC) are registered, non-profit associations that are formed by adult people who consume cannabis. They can be set up legally in any country where cultivation of personal amounts of cannabis has been decriminalised. In countries where this is not yet the case, CSC's can operate as an experiment in order to prepare for the moment when the laws on cannabis cultivation for personal use will change". The definition proposed by ENCOD underlines that transparency, democracy and non-profitability are essential characteristics of the model, and points at its potential for harm reduction:"Cannabis Social Clubs apply an active policy of prevention of harms and risks and promotion of safer methods of consumption of cannabis by its members" (see also: Belackova, Tomkova \& Zabransky, 2016).

Although CSCs can be found in many countries, the label often covers very different empirical realities. In fact, they have emerged as part of bottom-up (grassroots) initiatives (in Spain and Belgium, and several European countries), but they have also been part of top-bottom policies (as in Uruguay). Uruguay has adopted a legal framework for CSCs since December 2013. In the absence of a clear legal framework in European countries (such as Belgium and Spain), these organisations continue to operate at best in a grey zone (as discussed below). Many of such clubs chose to selfregulate and adhere to the five main principles as laid out in the above mentioned 'Code of Conduct': supply should follow demand, the CSCs should be non-profit, transparent, health-oriented and open to dialogue with authorities. However, other CSCs have adopted practices that diverge from those principles (BewleyTaylor, Blickman \& Jelsma, 2014; Decorte, 2015).

Any discussion of possible regulatory approaches starts with a clarification of the main objectives of regulation. In this paper we explicitly adopt a public health perspective: we assume that the debate about whether and how Cannabis Social Clubs should be regulated, should primarily seek to fulfil public health objectives: minimizing access, availability, and use by youths; minimizing drugged driving; minimizing dependence and addiction; minimizing consumption of cannabis products with unwanted contaminants and uncertain potency, and minimizing concurrent use of cannabis and alcohol, particularly in public settings (Pacula, Kilmer, Wagenaar, Chaloupka, \& Caulkins, 2014). Our starting point

\footnotetext{
1 The terms 'club', 'organisation' or 'association' are used interchangeably to refer to Cannabis Social Clubs throughout the paper.
}

is that any regulatory approach of CSCs should help to ensure their transparent and safe way of working, and to constitute a healthier alternative for the black market, enabling CSCs to apply an active policy of prevention of harms and risks and promotion of safer methods of consumption of cannabis by its members (Ritter, 2010).

In this paper we aim to describe and compare the legal frameworks and (self-) regulatory practices of CSCs in Spain, Belgium and Uruguay (see also: Pardo, 2014). We use the normative definition put forward by the cannabis movement (in this case, ENCOD) as a starting point. Aspects included in our comparative analysis are the domestic legal framework, the establishment procedures or practices, the characteristics of the formal organisation and management of the clubs, and their cannabis cultivation and distribution procedures. The objective of our comparative analysis is to investigate how CSCs operate in each of these countries, taking into account both the legal framework and the self-regulatory practices. To foster discussions about how one might regulate CSCs from a public health perspective, we conclude this paper with a discussion on the balance between adequate governmental control and self-regulatory competences of CSCs.

Spanish cannabis activists established the first cannabis associations in the early nineties, ${ }^{2}$ and in the first decade of the 21st century the number of Cannabis Social Clubs increased in a linear fashion, with the model spreading throughout Spain (Parés \& Bouso, 2015). While no official source has, to our knowledge, information on the exact amount of operating CSCs in Spain, based on previous estimates (e.g., Munoz Sánchez, 2015), informal sources and expert interviews we estimate that there may be between 800 and 1.000 CSCs currently open and distributing cannabis and other cannabis derivatives (January 2016). ${ }^{3}$ Catalonia and the Basque Country are the autonomous regions where CSC presence is more extended. The Spanish model soon began being introduced by activists in other European countries, in particular Belgium, but also in the United Kingdom, and even in France (Bewley-Taylor et al., 2014) - although little is known about the functioning of CSCs in the two latter countries. In Belgium, a first mapping by Decorte (2015) pointed to the existence of five CSCs active as of February 2014. While some of those clubs have meanwhile ceased their activities, new CSCs have emerged. An ongoing study by Pardal (forthcoming) has, at the time of writing, identified seven active CSCs. In Uruguay Cannabis Social Clubs are now allowed under the new cannabis law approved in December 2013 (Montañés, 2014). In Uruguay, at November 2016, there are 27 CSCs that fully comply with the regulations and therefore are completely legal. Other clubs are currently undergoing the process of formalisation before the governmental cannabis regulation body, i.e. the Institute for the Regulation and Control of Cannabis (hereinafter IRCCA). There might also be other clubs operating bypassing the regulation entirely, but it is virtually impossible to determine their number.

The data used for this analysis stem from independently conducted local studies by the authors in their respective countries, with different research designs. Therefore, data were not collected through identical data collection methods. The data on the Spanish CSCs (collected by co-authors Sanchez and Pares) are based on an analysis of the multiple regulatory proposals recently developed in Spain, a review of the literature, interviews with relevant political and social representatives,

\footnotetext{
2 The first known association of this type was ARSEC ("Asociacion Ramon Santos de Estudios del Cannabis") which was established in 1991, adopting the designation of "association for the study of cannabis" (Marín, 2008).

3 In addition, we have also consulted the national registry of legal associations and identified nearly 1000 registered CSCs so this estimate seems plausible.
} 
media content analysis and the monitoring of the recent CSCs evolution - conducted since January 2014. Beyond regular conversations in the context of that monitoring fieldwork, the authors conducted 10 face-to-face semi-structured interviews with directors of CSCs in Catalonia between March to December 2015. The data on the Belgian CSCs (collected by co-authors Decorte and Pardal) are based on an exploratory study conducted by Decorte circa 2014 (Decorte, 2015), based on a review of the international literature, of the internal documentation and media reports on the Belgian CSCs, as well as on face-to-face interviews with the directors of the five CSCs operating at the time, and field visits to those clubs (see also Decorte, 2015). These data have been complemented with additional desk research in the context of an ongoing study by Pardal (forthcoming). The data on the Uruguayan CSCs (collected by co-authors Boidi and Queirolo) are based on a series of eight interviews (seven of them face-toface and one by phone) with CSCs members and authorities and on documentary research (see also Queirolo, Boidi \& Cruz, 2016). Data were collected from March to August 2015. Despite CSCs being legal in Uruguay, there is no public directory that allows one to directly reach them. In order to gain access to as many clubs as possible, the Uruguayan team followed different strategies: personal networks, existing bonds with pro-cannabis regulation activists, references from other clubs, and previous contacts with frequent cannabis consumers that were made during a previous study (Boidi, Queirolo \& Cruz, 2015). A standardised questionnaire was used in the interviews, based on the instrument developed by Decorte (2015).

\section{The domestic legal framework for CSCs: the case of Spain, Belgium and Uruguay}

In order to better understand some of the characteristics the clubs have adopted in these three different countries, which we turn to in Section: The CSC model, it is important to consider the specific the legal context in which they have emerged and developed to date. In Spain there is no nation-wide regulation applicable to the activities of the CSCs. Nevertheless, the Spanish drug regulatory framework has several peculiarities that have allowed the emergence and development of the CSC model in the country (Marín, 2008) (although jurisprudence has recently pointed in a different direction). The CSCs have based their activities on two legal arguments: (1) that personal and private drug use has no criminal relevance within the Spanish legal system, and (2) the so-called 'shared consumption doctrine' developed by the Supreme Court (Barriuso, 2011; Díez \& Muñoz, 2012; García and Manjón-Cabeza, 2009; Manzanera et al., 2000). The use and possession of cannabis (as with the rest of controlled substances) is not punishable under Spanish criminal law (in the case of possession, as long as it is intended for personal consumption). ${ }^{4}$ It is the commercialisation of those substances that effectively constitutes a criminal offence, according to article 368 of the Spanish Criminal Code. The CSCs thus have built on these premises to produce cannabis that is distributed on a nonprofit basis among a closed circuit of adult users. While a number of autonomous regions and municipalities have sought to introduce guidelines or local regulation of certain aspects of the activities of these organisation, no legislative change has been introduced at the national level (Parlamento de Navarra, 2014; Parlamento Vasco, 2014; X, 2015; Generalitat de Catalunya Departament de Salut, 2015; Reyero \& Carra, 2014).

\footnotetext{
${ }^{4}$ Under the Organic Law 4/2015 on the Protection of Public Security, drug use and possession in public places, are punishable with fines that might range from 600 to $30.000 €$, even if not intended for traffic.
}

The CSC model has also not been object of regulation to date in Belgium (Decorte et al., 2013). In fact, there is some uncertainty as to the legality of the activities of the clubs operating in the country, as these have been exploring the flexibility and ambiguity within the domestic drugs legislation (Decorte et al., 2014; Gelders \& Vander Laenen, 2007; Kilmer, Kruithof, Pardal, Caulkins, \& Rubin, 2013; Pardal, 2016). In Belgium, the possession, cultivation and trade of cannabis is prohibited (1921 Law on Narcotic Drugs). Nevertheless, a 2005 Ministerial Guideline attributed the lowest priority for prosecution to the possession of cannabis under specific circumstances. Accordingly, an 'user amount' of up to $3 \mathrm{~g}$ or one cannabis plant may be tolerated (i.e., receive the lowest priority for prosecution), where this possession does not result in disturbance to the public order and in the absence of aggravating circumstances. ${ }^{5}$ The Belgian CSCs have argued that they are operating within the limits established by that Ministerial Guideline by cultivating one plant per member and that therefore their activities should receive the lowest priority for prosecution. However, the application of the Ministerial Guideline to the clubs' collective cultivation remains disputed.

Cannabis clubs are legal and completely regulated by the government in Uruguay. They are one of the three ways in which the Cannabis Law (Law 19,172) regulating the production, distribution and consumption of cannabis allows nationals who are at least 18 years old to obtain cannabis. The CSCs need to go through a series of steps to be granted authorisation to operate by the Institute for the Regulation and Control of Cannabis (IRCCA), which is the government institution overseeing all (legal) cannabis operations in the country. The clubs must first constitute a nonprofit organisation (stating as its sole purpose the cultivation and distribution of cannabis among its members), and complete the mandatory registry with the Registry Office at the Ministry of Education and Culture (i.e., the government body that keeps record of non-profits of all sorts). Once the Ministry of Education approves the registry, the clubs must register with IRCCA (2014), which will ultimately approve the club opening after inspecting their premises and crop plan. In comparison with the other two cases under study in this article, only Uruguayan CSCs follow such an authorisation procedure.

\section{The CSC model: self-regulatory practices in Spain and Belgium, and legislative requirements in Uruguay}

In the following sections we describe the known practices of CSCs in Spain, Belgium and Uruguay. We address both the supply cycle of the clubs, from the recruitment of growers to the distribution of cannabis to the members, as well as the internal structure, organisation, and house-rules of the CSCs in the three contexts.

\section{The establishment of a CSC}

\section{Spain}

The path of creation and development of a CSC generally follows a set of steps. It begins with the CSC foundation and recording in the national/regional registry of associations, a requirement that any other association must fulfil (minimum 3 people involved). The CSCs formally adopt a non-profit status, and the clubs' bylaws

\footnotetext{
5 The possession of cannabis in prison, in youth protection institutes, in educational centres and surrounding area, or the blatant possession of cannabis in a public space are examples of situations that are understood to disturb the public order (Decorte, 2015; EMCDDA, 2015; Kilmer et al., 2013). The possession of cannabis in the presence of minors, the involvement of a criminal organisation or causing harm/death to another individual constitute aggravating circumstances (Decorte, 2015; EMCDDA, 2015; Kilmer et al., 2013).
} 
explicitly include the shared cultivation and distribution of cannabis among their members as one of the association's goals. The next step is the approval of a collective cultivation agreement by its members.

As there is no specific formal regulation for CSCs in Spain, as explained above, there are no nation-wide criteria with regards to the CSCs locations. With that said, a few city councils (mainly in Catalonia) have developed municipal ordinances that do regulate some aspects of the CSC model, including the distance among the various clubs, as well as between CSCs and education and health facilities. The criteria used by the different municipal ordinances are not homogeneous, and the distances requested differ: for instance, from $1 \mathrm{~km}$ to $100 \mathrm{~m}$, in the case of the distance imposed between CSCs.

Talking about a "Spanish CSC model" is thorny. In a context of legal uncertainty and in the absence of a specific and comprehensive regulation, multiple versions of the model have emerged and coexist. Reliable data and empirical studies on this/these realities are also missing. Over the years, several CSC leaders and activists have formed CSC federations, and developed good practice codes and self-regulation initiatives (Arana, 2013; CATFAC, 2014; FEDCAC, 2013). There are at least 12 regional CSCs' federations in Spain. It is difficult to estimate the proportion of active CSCs that are federated, but those seem to be a minority. The autonomous region most known by the authors, Catalonia, has two CSC federations which gather around 25 CSCs each - this while the estimated total number of clubs in that region is at about 400 .

Some of the guidelines issued by the CSC federations, including those of Federació d'Associacions de Cànnabis de Catalunya, the Basque Institute of Criminology and Federació d'Associacions Cannàbiques Autoregulades de Catalunya (Arana, 2013; FEDCAC, 2013; CATFAC, 2014) address aspects such as the maximum total number of members per club (e.g., according to the most restrictive guidelines that would correspond to 650 members), the maximum quantity of cannabis distributed monthly to each member (e.g., between 60 and $90 \mathrm{~g}$, approximately), including a residence criterion for membership of the clubs (e.g., in some cases, members must be current residents in the city where the clubs are based; in others, membership is open to residents of the Schengen area, ${ }^{6}$ with a waiting period of two weeks, in order to avoid tourists), and defining protocols for cannabis transportation, and security. Despite those efforts, the lack of regulation has also fostered opportunism and excess, such as CSC promotion among tourists, the sale of cannabis beyond the typical CSC practices, or the neglect of good relations with the community. Disputes among CSC leaders about some of those practices have sometimes occurred too.

\section{Belgium}

In Belgium, CSCs have tended to register as non-profit associations in the national registry of associations. While this is of course not a mandatory requirement, all the five CSCs identified by Decorte (2015) had been formalised as such. Ongoing research by Pardal (forthcoming) has confirmed this tendency also with the more recent CSCs. The clubs are generally founded by at least three individuals who constitute the 'board of directors' of the club (e.g., President, treasurer, secretary). In their bylaws, the CSCs generally make explicit reference to the goals and key activities of the

\footnotetext{
${ }^{6}$ The Schengen Area is the area composed of 26 European states that have officially abolished passport and any other type of border control at their mutual borders. The area mostly functions as a single country for international travel purposes with a common visa policy. The area is named after the Schengen Agreement. States in the Schengen Area have eliminated border controls with the other Schengen members and strengthened border controls with non-Schengen countries.
}

association, including the cultivation and distribution of cannabis among their members.

No particular formal rules with regards to the location of the CSCs are applied in the Belgian context. While circa February 2014 most clubs reported officially renting buildings or parts of buildings for the official seat of the organisations (Decorte, 2015), at the time of writing, we encounter a different picture. We found that all but one CSC has its own separate premises Pardal (forthcoming). The remaining clubs operate from the personal address of one of the directors, or rent a location for specific gatherings and activities of the clubs (e.g., internal meetings, cannabis distribution moments).

In the absence of legislation or regulation specifically applicable to the CSC model (see Section The domestic legal framework for CSCs), the development of working practices and rules has mainly been shaped by those involved in the management of the CSCs (Pardal, 2016). To date, no federation of CSCs has been created in Belgium, but there have been plans to do so in the future (Decorte, 2015). Most Belgian CSCs are also members of ENCOD.

\section{Uruguay}

Uruguayan regulation requires each CSC to first register as a nonprofit organisation, for which it needs to comply with an extensive list of legal requirements. For instance, the club needs to select a name which must include the expression 'cannabis club' in it, and it must also provide a valid address. The non-profit organisation must be established by a foundational assembly constituted by at least 15 (and no more than 45) members. That assembly appoints the management structure of the CSC: the Board and the Auditing Committee. All the proceedings from the foundational assembly must be registered in the club's official record books and certified by a public notary. The notary certification, together with the club's original record books and proof of address must be submitted to the Registry Office at the Ministry of Education.

Only once the Registry Office approves the application and grants the club the status of legally registered non-profit, the CSC can apply for registration before the IRCCA. The registry with IRCCA does not actually take place at IRCCA offices, but rather it begins at the Uruguayan Postal Service, where the CSC authorities must submit all the documentation and certification granted by the Ministry of Education, together with their 'Crop Plan' describing the technical and safety features of the plantation, as well as a description of the club premises and security measures. Due to their widespread presence throughout the territory, the Postal Services offices were chosen by the government as the go to spot for cannabis registration: cannabis growers must also register there. The Postal Office serves only as a more accessible entry point for the registry, but it is actually IRCCA who will receive and analyse the submitted application, and grant the authorisation to operate upon inspection of the club premises.

Cannabis clubs are just becoming official, with only two of them having received complete approval to date (March 2016). By law, a federation must be constituted by several organisations (at least 3 ). Since most Uruguayan CSCs have not completed the process of becoming formal organisations, therefore they cannot form a federation (yet). However, there is a cooperative spirit among those involved, and members of some cannabis clubs are grouped under the Federation of Cannabis Growers. This federation reunites self-growers, members of CSCs and representatives of NGO's working in risk reduction. The federation representatives are in touch with government officials and they claim to inform the cannabis policy implementation process (X, 2014). The operation of the clubs is heavily regulated by law, leaving little space for selfregulatory practices. For instance, CSCs cannot be located within $150 \mathrm{~m}$ of education or addiction treatment centres, and they must be at least $1.000 \mathrm{~m}$ away from other cannabis clubs' headquarters. 
House-rules and internal organisation of a CSC

Spain

Generally, the clubs have adopted several membership requirements: the candidate members need to complete and sign a membership form; they are also asked to declare being over 18 years old (and in some cases, over 21), and being a regular cannabis user. The application must be supported by a person who is already a member of that association. There is no actual restriction to becoming a member of more than one CSC. Most of these members use cannabis for recreational purposes.

Medical cannabis users have also sought to join CSCs. While there is no specific requirement for one to enrol as a medical user of a CSC (for instance, no special accreditation from a doctor is requested), it is common that medical users present a medical certificate including their clinical history or showing that they suffer from one of the pathologies recognised by the International Association for Cannabinoid Medicines (IACM). It is also a common practice for CSCs to grant the medical members a discount on the cannabis price or to allow them to receive larger amounts of cannabis than recreational users (if necessary). To our knowledge, there are very few clubs who admit only medical cannabis users.

Generally, Spanish law does not impose any limit of members to associations in Spain. This helps explain why nowadays there are CSCs in the country with more than several thousand members (Mumbrú, 2015). As mentioned above, some of the good practice codes recommend a maximum number of 650 members (Arana, 2013; FEDCAC, 2013; CATFAC, 2014).

In general, CSCs do not admit non-residents, although it is well known that some of them (e.g. in Barcelona) advertise among tourists (ABC, 2014). There is usually an annual fee that ranges between 10-30 euros, although some clubs do not charge any fee.

Most CSCs allow their members to consume inside the premises of the clubs. While it seems that the CSCs may have adopted different practices with regards to opening hours, or the consumption of alcohol within the clubs' premises, more research is needed to shed light into these aspects.

Advertisement or promotion of cannabis consumption is explicitly prohibited by the Spanish Criminal Code. Most CSCs do not have a dedicated website, and in the cases where they do, the contents of such webpages tend to be limited to information about the name, location and contact details of the club. Some of the CSCs use social networks like Facebook or Twitter for activism purposes, sharing information about the detention of staff members, trials, or about policy developments. In some cases, the clubs keep only internal communication with their members, for instance through an internal mailing list or newsletter, using WhatsApp groups, or through closed groups on Facebook. Other clubs do not maintain such (online) lines of communication with their members.

\section{Belgium}

Membership of a CSC in Belgium is open to adult users (at least 18 years old) of cannabis (recreational and/or medical) residing in Belgium Pardal (forthcoming). Some Belgian CSCs have limited membership to users who are at least 21 years old (Decorte, 2015). The admission process includes the completion of a membership form, where candidate members are asked to confirm that they are cannabis users (prior to joining the CSC), and declare that they are aware of the applicable drugs legislation in Belgium and that they are voluntarily applying to join the CSC (Decorte, 2015). The candidate members are also invited for an intake interview, where a representative(s) of the board of direction provides information about the functioning of the club, and discusses the patterns of cannabis use of the candidate members. CSC membership is only possible for one club at a time - although the Belgian CSCs acknowledge that this exclusivity criterion is difficult to implement in practice Pardal (forthcoming). New members are informed that the sale of all or part of the cannabis received through the club to non-members would violate the club regulations, and would thus lead to the exclusion from the CSC.

All the Belgian CSCs admit medical users of cannabis as well (Decorte, 2015). In 2015, two new clubs were established in Belgium that focus exclusively on the supply of cannabis for medical users (Pardal, forthcoming). Specific requirements as to the membership of medical users vary among clubs. In some cases, the clubs request a medical prescription and/or a medical file which support the use of cannabis in the treatment of a specific medical condition. During the intake interview, these issues are also discussed. One of the larger clubs organises a separate intake interview for candidate members who use cannabis for medical reasons. Some clubs (including one of the new medical CSCs) organises also regular follow up sessions with their medical users (Pardal, forthcoming).

The CSCs tend to define a minimum of three members, but no maximum limit has been established so far. The actual number of members varies per club, with smaller clubs gathering over 10 members, and the largest one counting with 237 members (circa February 2014) (Decorte, 2015). Most clubs tend to have a waiting list of candidate members, and thus these CSCs are likely to increase size.

Circa February 2014, the active CSCs in Belgium requested an annual membership fee of $25 €$ (Decorte, 2015). CSCs members who also contributed to the cultivation process were in some cases granted a reduction of their membership fee. Only members and accompanying adults are allowed to enter the premises of the CSCs.

According to Belgian law, providing a location for the consumption of prohibited substances constitutes a punishable offence, and thus it is perhaps unsurprising that the official policy of most CSCs does not allow for the consumption of cannabis inside the premises of the clubs. It should be noted though that there may be differences between smaller and larger clubs, in that the former may allow for the shared consumption of cannabis at a members' private house for instance (Decorte, 2015). It is not clear whether such practices are presently taking place.

Typically, the Belgian CSCs have websites where the purpose of the organisation is outlined, including references to the cultivation and distribution of cannabis, and other information (e.g., membership form, CSC by-laws, etc.) is publicly made available (Decorte, 2015). The clubs also keep communication with their members through social network platforms (such as Facebook) and through mailing lists.

\section{Uruguay}

The Uruguayan cannabis law is very restrictive in terms of access to the substance. Membership of CSCs in Uruguay is open to nationals with 18 years or more, and all users must be registered with IRCCA in order to legally obtain cannabis. There are three ways of acquiring cannabis: self-grown, through CSCs and by purchase in pharmacies. These three ways of access are mutually exclusive: individuals registered as self-growers cannot become members of CSCs nor become registered for purchasing at pharmacies. Likewise, individuals cannot belong to more than one CSC at a time. The IRCCA keeps record of all registered users in order to prevent individuals from registering under more than one form of access or in more than once CSC. The main objective of this feature of the cannabis policy is to cap consumption of cannabis, currently set at a maximum of $40 \mathrm{~g}$ per individual per month.

Admission processes are not well defined, but trust and recommendations are the two main criteria mentioned for the admission of new members. In most CSCs, a candidate member must be introduced by an existing member. As a result, CSC 
membership in Uruguay is essentially composed by friends or relatives.

Some clubs have medical members, but these are just a few individuals in only a couple of clubs. The regulation of the cannabis market was mainly devised for recreational cannabis, and it is only recently that the protocols for medical cannabis have started being developed. To our knowledge, there are no clubs specialised in medical cannabis, although some of them cultivate strains and (illegally) produce by-products (such as tinctures) for medical purposes.

The law establishes a minimum $(n=15)$ and a maximum $(\mathrm{n}=45)$ number of club members, as well as a maximum of flowered plants allowed in the club premises at any given time (i.e., 99 plants). The regulation also establishes a maximum amount of cannabis per club member ( $480 \mathrm{~g}$ per member/year) and the mandatory disposition of any remaining produce.

Fees vary significantly depending on the club, from 26 to 92 US dollars monthly, a price that guarantees access to $40 \mathrm{~g}$ of cannabis per month (prices in August 2015). In several clubs fees are fixed and mandatory, but in others members pay differential fees depending on the amount of cannabis they receive. In some clubs fees can be reduced based on members workload for the club.

Consumption is allowed in CSCs facilities, and interviewees declare that while that is a frequent practice, the clubs do not really have a policy or rules guiding the consumption in the premises of the CSC. Consumption in the CSCs happens mostly when Clubs organise parties and meetings to test the product; when that is not the case, most consumers choose to take the product home. Club representatives were unable to reliably estimate the number of members who consume in the premises nor the frequency with which they do it. However, the general impression they convey is that the Uruguayan CSCs are primarily sought for obtaining cannabis, and the possibility of consuming it in the premises is not one of the most valued features of the clubs. There are no clear rules about consumption of other substances in the premises of the clubs, but it is clear from the interviews that consumption of alcohol is allowed, at least during parties.

The clubs' activities are promoted among members by email, Facebook or the free instant messaging application WhatsApp, which is very popular in Uruguay. By regulation, advertising of club activities to non-members is not allowed. It is also prohibited to advertise or promote the activities of the club on facades or in any other public spaces. None of the clubs surveyed owns a website, but two of them have Facebook accounts. Of those, only one is a public Facebook profile and it is not devoted to the specific activities of the club but rather to raise awareness about cannabis consumption in general and the Uruguayan regulation in particular.

\section{Management of a CSC}

\section{Spain}

By law, Spanish associations should have a democratic, horizontal management structure, according to which all the important decisions are to be taken at general assembly meetings. The associations should also organise at least one general assembly meeting per year. While these practices were followed by the first CSCs (constituted until 2010), since then new actors have emerged and those criteria have had a more relaxed interpretation. Nowadays, there is thus a wide range of views with regards to the management of CSCs. For instance, it is quite common that the CSCs are managed by a small group of people, and that the annual general assembly is not really the place where important decisions are discussed. In those cases, the group of CSC managers tend to be the one who initially (financially) invested in the set up of the CSC.
Most clubs hire paid staff who work on the various activities of the clubs, ranging from cultivation, transportation and distribution tasks, to the day-to-day maintenance of the CSCs (e.g., cleaning, security and entrance control). Approximately, a CSC with 700 members tends to employ 10 staff members.

While all CSCs are registered as non-profit associations in the official registry of associations, there have been several cases of malpractices and lack of transparency regarding the real make of profit, especially during the period of expansion of the model. This has been the root of some tension between the representatives of clubs that try to work on a non-profit basis, and employ a more horizontal decision-making structure, and the representatives of other clubs which do not necessarily adhere to such practices. Again, while some CSCs follow the good practice codes promoted by the federations of CSCs (FEDCAC, 2013; Arana, 2013; CATFAC, 2014), most apply their own rules.

\section{Belgium}

While the administration of the Belgian CSCs has been described as democratic, the extent to which members participate in the decision-making process of these clubs may vary across clubs. Formally, all clubs appoint a board of directors, which should report to the general assembly of members at least once a year. In previous research we have found that smaller clubs tended to concentrate the administrative, organisational and financial management work on a few founding members, while the largest and oldest club was able to allocate certain tasks to specific working groups within the club (Decorte, 2015).

The CSCs have in most cases relied on the assistance of volunteer members, and generally do not hire paid staff to assist with administrative tasks and/or the cultivation process, with exception of the larger club which has contracted staff. The growers, as described in Section Cannabis cultivation within a CSC are usually compensated for their labour by the CSCs.

The clubs have reported operating on a non-profit basis, in accordance to the by-laws of the organisations, with any financial gains being reinvested in the clubs to support the organisation's activities (e.g., lobbying efforts, social activities, medical and legal consultancy fees, etc.) (Decorte, 2015). To date, there has been one known case of a CSC which arguably misused its non-profit status (Flemish newspaper Het Laatste Nieuws, 11 December 2015). Nevertheless, some of the CSCs have voiced concern about the possible emergence of 'shadow clubs' oriented by other (for-profit) principles (Pardal, forthcoming; Decorte, 2015).

\section{Uruguay}

According to the law, Uruguayan CSCs must have a board of directors that executes the guidelines provided by the general assembly of members, which must reunite with certain periodicity. In reality, the general assembly of members rarely meets (with the exception of the first foundational assembly where the protocol is signed), and there are only a few club members involved in the club's daily activities. These highly involved members might or might not be part of the board of directors. The majority of the members only gather to collect their share of cannabis when it is available. This is a case of strict regulation that has not (yet) been met by equally strict control and enforcement - it does not however represent a major challenge for policy implementation. The bigger issue at stake here is diminished participation which posits burdens that are practical - not legal - to the clubs daily operation.

Most clubs surveyed do not have paid personnel, and therefore the workload is shared among the most committed members (which in some cases are waived their membership fees in exchange for their service). Exceptionally, clubs may call all 
members to collaborate in key activities such as during the harvest period. The clubs that have paid personnel count with a gardener and an administrative staffer. In those cases, they are the ones responsible for the CSC daily functioning. The general assembly of members is called when a major change must be discussed (e.g., moving the club premises) or once a year for the mandatory accountability meeting.

By definition, Uruguayan CSCs are non-profit organisations, as they are constituted as civic associations, not as business entities. None of the club representatives we interviewed expressed intention to make profit from the clubs' activities.

\section{Cannabis cultivation within a CSC}

\section{Spain}

The CSC rents or buys everything needed for growing and harvest, including land, buildings and equipment. The quantity that should be cultivated is estimated with basis on the predicted amount consumed by each member per month. In Spain, when a new member joins a CSC, he/she has to indicate a quantity of cannabis that he/she normally consumes during one month. The total amount of plants harvested is calculated with basis on these individual estimates in order to provide sufficient cannabis to the members. As some CSC have more than 5.000 members, it is perhaps unsurprising that some CSCs may have vast plantations sites, with more than 1.000 plants.

The majority of the CSCs grow the cannabis in hidden venues, with high security controls. While some of the CSCs' growers are members of the club, others are formally hired as gardeners (which is the official legal figure). However, in practice there may be some flexibility in terms of the formalities with growers. The crops and the transport of the cannabis remain an aspect of CSCs' work which is the most vulnerable to police intervention. It should be noted that not all the CSCs grow their own cannabis at all times, as the CSCs base their activities on the 'shared consumption doctrine' (discussed in Section The domestic legal framework for CSCs) which leaves the users unpunished under certain circumstances, regardless of the way the substance (cannabis, in this case) is obtained. In some cases the clubs buy the cannabis in the black market. Those CSCs and their lawyers have claimed that such practice does not constitute a legal offence as no profit is generated from the initial purchase and distribution of cannabis among the associate members. More information about the number of clubs engaging in such practice is not available.

Every CSC has its own chart of cannabis products, with dozens of strains, many types of cannabis derivatives, extractions, edibles, etc. The CSC main product remains herbal cannabis, either from indoor or outdoor cultivation. However, in some cases the clubs also produce cannabis resin (mainly hashish, but also other resins extractions with butane gas and/or other dissolvent, reportedly containing a THC concentration of 80 or 90\%). The clubs increasingly prepare other cannabis products such as alcohols, creams, oils, tinctures or sweets, fostering alternative methods of use. Most clubs offer vaporizers as well.

Regarding the quality control processes of the clubs, a few CSCs test their cannabis in specialised labs, but the majority of them do not (see also: Belackova et al., 2016). The CSCs analysing their products usually test the percentage of cannabinoids, the presence of additives and contaminants, as well as other microbiological tests.

\section{Belgium}

In Belgium, each plant grown by the CSC has an individual record, a so-called 'grow card', indicating its ownership by one of the members of the club (Decorte, 2015). The cultivation of cannabis has been organised in different ways by the Belgian CSCs, with some opting for synchronous production (i.e., growing all the plants at one time and distributing the harvest among the members every 3 months for instance) and others cultivating the cannabis asynchronously, in order to being able to provide (smaller amounts of) cannabis on a more frequent basis. The Belgian CSCs report cultivating a number of plants corresponding to the number of members (i.e., one plant per member), which relates to the legal framework in which the CSCs operate in Belgium, as discussed in the Section: The domestic legal framework for CSCs.

The cultivation of cannabis by the CSCs is generally a task for which some of the clubs' members volunteer. The growers are thus members of the CSCs, and are generally compensated for their activity as growers. The clubs tend to draft a protocol and/or contract with their growers, defining for instance the number of plants to be grown per cultivation site and per $\mathrm{m}^{2}$, the minimum conditions for each cultivation site (e.g., cultivation site must be a private and enclosed space, not accessible to third parties or minor), or the growing process (e.g., organic cultivation, technical equipment to be checked by the club) (Decorte, 2015; Pardal, forthcoming). Growers are not allowed to grow cannabis for others, but may grow one plant for their own personal use.

Circa February 2014, all the CSCs were growing cannabis indoors, and kept several small cultivation sites (Decorte, 2015). Key reasons for dispersing production across different sites include reducing the risk of shortage due to plant disease or theft, and minimizing potential law enforcement and judicial impacts, as according to the classification used by the Belgian police, plantations containing up to 49 plants are seen as 'microplantations' or 'mini-plantations' (Decorte, 2015). The clubs' decisions on which strains of cannabis are cultivated are based on growers' and members' preferences.

The Belgian clubs focus on the production of herbal cannabis, but in some instances (mainly involving medical users) the CSCs provide also information about how to prepare other cannabisbased products to their members (e.g., cookies, tea, oil). The CSCs tend to produce several strains of cannabis. A few of the active clubs offer also vaporizers at wholesale prices (Decorte, 2015; Pardal, forthcoming).

The clubs have reported experiencing problems with growers in several occasions. Thefts, non-adherence to the production protocol, low quality cannabis, have been some of the issues mentioned by the CSCs with regards to their relation with growers (Decorte, 2015). Most clubs use somewhat rudimentary quality control mechanisms, but would like to introduce more standardised quality control practices. Generally, a representative from the CSC visits and inspects the cultivation sites at different points in time during the growing process (Decorte, 2015).

\section{Uruguay}

CSCs are allowed to cultivate up to 99 flowering plants at a time according to Uruguayan law. This threshold relates to an estimate of how many plants may be necessary to produce up to $40 \mathrm{~g}$ for each of the 45 members that a club is authorised to have. However, interviewees from most clubs declared that they have fewer plants than that. Clubs decide on their cannabis production based on the number of members: they all target to produce enough cannabis to supply $40 \mathrm{~g}$ per member per month, which is the maximum amount allowed by law. The regulation also establishes a mandatory disposition of any remaining produce.

In all the clubs surveyed the gardener is a member of the club. In some cases this person receives a small salary for the job (but it is unclear whether the gardener is in fact registered for social security, following all the official formalities). 
Most CSCs in Uruguay combine indoor and outdoor cultivation. Indoor cultivation is mainly used during winter, and outdoor during the summer. The clubs prefer to combine both to minimize the risk of a drought period, a plague or simply a bad harvest. Most clubs are still quite inexperienced in cannabis cultivation and therefore their productivity varies a lot: from 50 to $200 \mathrm{~g}$ per plant in indoors facilities, and from $350 \mathrm{~g}$ to $3 \mathrm{~kg}$ for outdoor cultivation.

The Uruguayan law only allows clubs to produce cannabis, not derivatives. The clubs decide what to plant either based on their members' expressed preferences (for the most sophisticated and well-organised clubs) or on whatever seeds or strains they have available (e.g., from the members own self-grown plants, or from seed banks). Most surveyed clubs report having only a few strains (between 5-8), while others - again, the well-organised ones report having 15 or even more than 20 strains. Two of the clubs surveyed organise tasting events where members get to try and evaluate the products. In those cases, the next plantation is decided based on the members preferences expressed during those tastings events.

Despite one of the stated advantages of being a CSC member usually is knowing the characteristics of the consumed cannabis, there is little knowledge to date about the levels of THC and CBD among the Uruguayan CSCs. Only a few clubs have sent their plants to be tested, and members are only aware about the information that the seed banks provide. Even members that consume cannabis for medical purposes do not have information about the cannabis they are using.

\section{Cannabis distribution within a CSC}

\section{Spain}

Members can generally collect cannabis from the CSCs at any given moment during the opening hours of the club, without the need for a prior request or notice.

The CSCs allow the provision of a range between 60 to $90 \mathrm{~g}$ per member, per month. Most of them allow $90 \mathrm{~g} /$ month, which corresponds to $3 \mathrm{~g}$ /day for each member. Exceptions for medical users in need of a higher amount of cannabis may be permitted in some cases. The CSCs' members pay a proportionate fee depending on the quantity they collect at each withdrawal.

The fees are used to cover CSC production costs, storage and management. Being non-profit organisations, all economic revenues are reinvested in the associations (Barriuso, 2011), although there actually have been multiple cases of misconduct in which the clubs have actually generated revenues. The price per gram varies significantly, from 4,50 to 15 Euros per gram. The extractions are more expensive, from 15 to 80 Euros per gram.

Only a few clubs, most of which are part of a CSC federation, provide additional information about the cannabis being distributed or cannabis use in general.

\section{Belgium}

The distribution of cannabis to the CSCs' members mainly takes place in bulk, at so-called 'exchange fairs'. Depending on the production cycles, CSCs organise exchange fairs every 4-6 weeks (asynchronous production) or every 2-3 months (synchronous production) (Decorte, 2015). CSCs supplying medical users have in some cases adopted different distribution practices, to ensure a more regular supply and/or facilitate distribution for those users who are not able to travel to the clubs' distribution points (Pardal, forthcoming).

The Belgian CSCs impose different limits with regards to the quantity of cannabis supplied (varying from $10 \mathrm{~g}$ to $30 \mathrm{~g}$ per month). Additionally, some clubs have introduced a different (i.e., higher) threshold for their medical members. Members contribute to the production, storage and administrative costs by paying a fee of 5-8€ per gram of cannabis received (Decorte, 2015).

Some of the Belgian CSCs distribute information about the type of cannabis supplied (genetic composition, physical and mental effects, description of odour, reviews from members, etc.) as well as the house-rules (Decorte, 2015). Additionally, information about sensible use of cannabis and treatment centres are provided by some of the clubs.

\section{Uruguay}

The law establishes a maximum amount of cannabis per club member ( $480 \mathrm{~g}$ per member/year). Under the Uruguayan model, clubs do not charge members per gram of cannabis; they charge a fixed monthly membership fee which grants individuals access to up to $40 \mathrm{~g}$ of cannabis per month. Among the clubs surveyed for this study, only one does not collect monthly fees but charges members per gram, at a price of around USD2 per gram of cannabis (for a maximum of $40 \mathrm{~g}$ per month). In other words, no matter how much you use, you pay the same in the majority of CSCs. This is a procedure that can certainly motivate more individual consumption, or a grey market by means of buying cooperatives: just one person is registered as a member but they share/sell their allotted monthly $40 \mathrm{~g}$ with/to other people.

There are three main ways in which CSCs distribute cannabis to their members. The most common one is to dispense cannabis in bulk at harvest. In those cases, all the yields from a given harvest are evenly distributed among the club members. Most clubs are at early development stages, and therefore they do not produce enough cannabis to reach the maximum of $480 \mathrm{~g}$ per year per user. To mitigate against this, they distribute all of what they produce each time. A second form of distribution is the monthly delivery. The more organised clubs establish a monthly date for distribution, and club members go to the premises to collect their share. Finally, one of the surveyed clubs delivers cannabis on demand: each member can access a maximum of $40 \mathrm{~g}$ per month, and pays according to the quantity received.

To date, clubs have been designed to provide mainly recreational cannabis. Some medical users complain that this is an important limitation of the model, especially in what regards the maximum amount allowed per member/year, which makes it difficult to develop by-products for medical use.

Some of the clubs surveyed declared their commitment to raise awareness within society on cannabis consumption and risk reduction among members. They provide information on responsible consumption and harm reduction strategies.

\section{Discussion}

Having described the different practices adopted by the CSCs operating in Spain, Belgium and Uruguay (Section: The CSC model), with reference to the legal context in which these have been developed (Section: The domestic legal framework for CSCs), in this section we highlight some of the common practices and emerging issues. While this analysis reveals important aspects which could inform potential future regulation of the model, a more comprehensive assessment of the functioning and effects associated with the model in each country is lacking. Our analysis is thus limited to the data collection efforts of the three research teams, and we acknowledge that some CSCs and their practices may not have been captured. Finally, we are also aware that the perspectives of CSCs' members (and growers) were not included in the country-research on which this analysis was based. Table 1 below provides an overview of our findings in each country, which we discuss in the following paragraphs. 
Table 1

An overview of CSCs' practices in Spain, Belgium and Uruguay.

\begin{tabular}{|c|c|c|c|}
\hline Country & Spain & Belgium & Uruguay \\
\hline Legal status & Unregulated & Unregulated & Regulated \\
\hline Number & Approx. 800-1.000 & Approx. 5-10 & Approx. 20 \\
\hline \multicolumn{4}{|l|}{ Establishment } \\
\hline Formal registration & National registry of associations & National registry of associations & $\begin{array}{l}\text { Registry Office at the Ministry of Education } \\
\text { Registry and IRCCA }\end{array}$ \\
\hline Official legal form & Non-profit association & Non-profit association & Non-profit association \\
\hline $\begin{array}{l}\text { Number of people } \\
\text { needed to start }\end{array}$ & 3 & 3 & 15 \\
\hline Location & $\begin{array}{l}\text { Different location restrictions in place } \\
\text { across municipalities }\end{array}$ & No restrictions in place & At least $150 \mathrm{~m}$ from education and treatment centers \\
\hline \multirow{3}{*}{$\begin{array}{l}\text { Federations and self- } \\
\text { regulatory practices }\end{array}$} & & & At least $1 \mathrm{~km}$ from other CSCs \\
\hline & Several federations & No federation & $\begin{array}{l}\text { No federation (but some joined the Federation of } \\
\text { Cannabis Growers) }\end{array}$ \\
\hline & $\begin{array}{l}\text { Good practice codes } \\
\text { ENCOD Code of Conduct }\end{array}$ & ENCOD Code of Conduct & \\
\hline
\end{tabular}

\begin{tabular}{|c|c|c|c|}
\hline \multicolumn{4}{|c|}{ House rules and internal organisation } \\
\hline \multirow[t]{6}{*}{ Membership criteria } & At least 18 or 21 years old & At least 18 or 21 years old & At least 18 years old \\
\hline & Sign membership form & Sign membership form & $\begin{array}{l}\text { Registered in IRCCA database as users acquiri } \\
\text { cannabis through a club }\end{array}$ \\
\hline & Prior regular cannabis users & Prior cannabis users & Introduced by an existing member \\
\hline & Introduced by an existing member & Only Belgian residents & Membership of one club only \\
\hline & Only Spanish residents (but in Barcelona & Awareness of Belgian legislation & \\
\hline & tourists have also joined CSCs) & $\begin{array}{l}\text { Membership of one club only (despite } \\
\text { difficult implementation) }\end{array}$ & \\
\hline \multirow{3}{*}{$\begin{array}{l}\text { Membership by } \\
\text { medical users }\end{array}$} & Medical users accepted & Medical users accepted & Medical users accepted \\
\hline & $\begin{array}{l}\text { No specific requirements (but some } \\
\text { members provide medical certificates) }\end{array}$ & $\begin{array}{l}\text { In some cases based on medical prescription } \\
\text { and/or medical file }\end{array}$ & No specific requirements \\
\hline & & New CSCs exclusively for medical users & \\
\hline \multirow{2}{*}{$\begin{array}{l}\text { Minimum/maximum } \\
\text { number of members }\end{array}$} & No limit applied & No limit applied & 15-45 members \\
\hline & CSCs up to thousands of members & CSCs up to over 200 members & \\
\hline Membership fees & Annual fee (with some exceptions) & Annual fee & Monthly fee \\
\hline $\begin{array}{l}\text { Cannabis } \\
\text { consumption at the } \\
\text { CSC }\end{array}$ & Yes & No & Yes \\
\hline \multirow[t]{2}{*}{ Advertising } & No & No & No \\
\hline & Internal communication with members & Internal communication with members & Internal communication with members \\
\hline
\end{tabular}

\begin{tabular}{|c|c|c|c|}
\hline \multicolumn{4}{|l|}{ Management of CSCs } \\
\hline \multirow{4}{*}{$\begin{array}{l}\text { Decision-making } \\
\text { structure }\end{array}$} & Board of directors & Board of directors & Board of directors \\
\hline & $\begin{array}{l}\text { At least annual general assembly } \\
\text { meeting (sometimes pro forma) }\end{array}$ & $\begin{array}{l}\text { At least annual general assembly meeting } \\
\text { (sometimes pro forma) }\end{array}$ & $\begin{array}{l}\text { At least annual general assembly meeting (de facto GA } \\
\text { rarely meets) }\end{array}$ \\
\hline & Different management styles & Different management styles & Management mainly by a few members \\
\hline & Paid staff is common & $\begin{array}{l}\text { CSCs rely mostly on volunteer work from } \\
\text { members }\end{array}$ & CSCs rely mostly on volunteer work from members \\
\hline Profit vs. non-profit & Non-profit (with exceptions) & Non-profit & Non-profit \\
\hline
\end{tabular}

Cannabis cultivation

Planning of production Based on consumption estimate by the members

Up to 99 flowered plants at a time

\begin{tabular}{|c|c|c|}
\hline & & ownership \\
\hline \multirow[t]{2}{*}{ CSC growers } & Mix of hired growers and members & Members of the clubs \\
\hline & Some clubs buy also from black market & \\
\hline \multirow{2}{*}{$\begin{array}{l}\text { Location and size of } \\
\text { cultivation sites }\end{array}$} & Indoor and outdoor cultivation & Indoor cultivation \\
\hline & $\begin{array}{l}\text { Cultivation sites of different sizes (larger } \\
\text { clubs may have more than } 1.000 \text { plants } \\
\text { per site) }\end{array}$ & Several (small) cultivation sites \\
\hline $\begin{array}{l}\text { Plants cultivated per } \\
\text { club/member }\end{array}$ & $\begin{array}{l}\text { Cultivation corresponding to the sum of } \\
\text { members' consumption estimates }\end{array}$ & 1 plant per member \\
\hline \multirow{2}{*}{$\begin{array}{l}\text { Types of products/ } \\
\text { strains of cannabis }\end{array}$} & Various cannabis products & Mainly herbal cannabis \\
\hline & Various strains & Various strains \\
\hline Quality control & Rarely tested via laboratory methods & $\begin{array}{l}\text { Rarely tested via laboratory methods } \\
\text { Growing protocol (contract between CSC } \\
\text { and grower) }\end{array}$ \\
\hline
\end{tabular}

Members of the clubs

Indoor and outdoor cultivation

Max 99 flowered plants per club (at a time)

Herbal cannabis only

Various strains

Rarely tested via laboratory methods 
Table 1 (Continued)

\begin{tabular}{|c|c|c|c|}
\hline Country & Spain & Belgium & Uruguay \\
\hline Legal status & Unregulated & Unregulated & Regulated \\
\hline Number & Approx. 800-1.000 & Approx. 5-10 & Approx. 20 \\
\hline & & & $\begin{array}{l}\text { "Crop Plan" (including legal requirements regarding } \\
\text { growing methods, phytosanitary management, use of } \\
\text { fertilizers, etc.) }\end{array}$ \\
\hline
\end{tabular}

\begin{tabular}{|c|c|c|c|}
\hline \multicolumn{4}{|c|}{ Cannabis distribution } \\
\hline $\begin{array}{l}\text { Frequency of } \\
\text { distribution }\end{array}$ & During opening hours of the club & $\begin{array}{l}\text { Mainly at exchange fairs (every 2- } \\
3 \text { months), but different practices } \\
\text { within medical clubs }\end{array}$ & $\begin{array}{l}\text { Different modes of distribution: after harvest; monthly } \\
\text { delivery; on demand }\end{array}$ \\
\hline & No prior notice needed & & \\
\hline Quantity limits & $60-90 \mathrm{~g} /$ per month (approx. $3 \mathrm{~g} /$ per day) & $10-30 \mathrm{~g} /$ per month & $40 \mathrm{~g} /$ per month ( $480 \mathrm{~g} /$ per year) \\
\hline Price per gram & $4,5-15 € / g$ & $5-8 € / g$ & In most cases, included in membership fee \\
\hline $\begin{array}{l}\text { Additional } \\
\text { information } \\
\text { provided upon } \\
\text { distribution }\end{array}$ & $\begin{array}{l}\text { Some provide information about } \\
\text { responsible consumption and harm } \\
\text { reduction strategies }\end{array}$ & $\begin{array}{l}\text { Some provide information about } \\
\text { responsible consumption and harm } \\
\text { reduction strategies }\end{array}$ & $\begin{array}{l}\text { Some provide information about responsible } \\
\text { consumption and harm reduction strategies }\end{array}$ \\
\hline \multicolumn{4}{|l|}{ Public profile } \\
\hline Media strategy & $\begin{array}{l}\text { Both low profile and high profile } \\
\text { (Federated clubs have more public } \\
\text { profile) }\end{array}$ & Both low profile and high profile & Both low profile and high profile \\
\hline
\end{tabular}

The establishment of a CSC

We found, for instance, that CSCs in the three countries have tended to complete a formal registration as associations in the relevant domestic registries - both as a result of a legal requirement (Uruguay) or on their own initiative (Spain, Belgium). While the clubs have also generally adopted a non-profit status, recent developments particularly in Spain suggest that formal controls may be necessary, especially with a view to promote public health objectives. Pacula et al. (2014) argue that the density of tobacco outlets is positively associated with smoking rates, particularly among youths, and that studies have shown a strong positive relationship between alcohol outlet density and alcohol misuse. Given the very different number of CSCs present in each country (see Table 1), it is difficult to conclude as to whether the number of possible CSCs should be capped by the legislator, and if so, at which range. Limitations with regards to the location of the CSCs (for instance, distance to schools and medical centres) as already included in Uruguayan legislation may be also considered.

\section{House rules and internal organisation of a CSC}

With regards to membership criteria, the clubs have to some extent developed similar practices, for instance admitting only adult cannabis users. The experience in the three countries indicates that restricting membership to nationals or residents of the country may help reducing 'drug tourism'. The creation of a centralised database of CSCs and their members (as it is the case in Uruguay) could be helpful for the application of that criteria, as well as to ensure that each cannabis user can enrol as member of only one club. At the same time, we are aware that creating such a registry may also bring an additional layer of bureaucracy for the CSCs and their members, and that cannabis users may be reluctant to complete the registration (for instance, for privacy reasons). The ongoing experience in Uruguay may provide additional information as to the feasibility and further design of this requirement.

The total number of members allowed per CSC is another issue to be considered in future regulation. It is likely that if clubs enrol thousands of members, they may lose sight of their non-profit goals and merge into large(r) enterprises, which is to some extent what has occurred particularly in Barcelona. However, it is also not clear if the limit currently imposed by the Uruguayan legislation (i.e., a maximum of 45 members) is practicable.

The CSC model emerged essentially with a focus on recreational use of cannabis, but in Spain, Belgium and Uruguay medical users have sought to join CSCs and many clubs have sought to accommodate their needs. In some cases these medical users must present a medical certificate or a prescription from a doctor but this is not necessarily common practice among most CSCs. Often the clubs apply other (less stringent) rules related to minimum age, maximum consumption limits, or they offer particular strains or cannabis products. In the absence of stringent quality controls of the cannabis distributed through CSCs to patients and in the absence of solid collaboration and information exchange between CSCs and medical specialists, it remains an open question whether it is a good idea to join medical cannabis and recreational cannabis under one setting. On the other hand, the debate about separate and differential regulation of recreational and medical cannabis clubs may also be complex, especially if one takes into account the conceptual confusion related to the use of medicines (i.e., pharmaceutical drugs) and drugs (i.e., illegal psychoactive substances), the wide range of medical conditions and symptoms that seem to be instigating medical cannabis use, and the phenomena of self-declared (but undiagnosed) medical cannabis use and self-medication practices. Moreover, some countries may have a regime for cannabis based on medical prescription that could be in conflict with the (medical) CSC model. Whether or not the supply of cannabis for medical purposes should and could take place in specialised CSCs is an important issue for future research.

CSC members in the three countries contribute to the running of the organisation with a membership fee. With regards to this aspect, two different practices have developed: on the one hand, clubs in Spain and Belgium have opted for an annual membership that covers the internal costs of managing and maintaining the CSC; on the other hand, the membership fee in Uruguay is paid on a 
monthly basis and covers also the amount of cannabis that each member will receive.

Advertisement of the CSCs activities is not allowed nor a common practice in any of the three contexts studied, a practice that could be confirmed and further supervised in future regulatory frameworks.

\section{Cannabis cultivation and distribution within a CSC}

Another set of issues which merit attention relate to the cultivation and distribution of cannabis by the CSCs. The quantity supplied by the clubs in the three countries seems to be somewhat related to the consumption estimates made by their members (although within the quantity limit imposed by law in the case of Uruguay), which is consistent with the 'supply-follows-demand'philosophy of ENCOD's Code of Conduct mentioned earlier. However, as we noted, in practice there might have been deviations to this principle. Introducing a maximum quantity per member the route taken by the Uruguayan legislator, may thus be one possible way to formalise the ongoing practices of (often federated) clubs adhering to the 'Code of Conduct' for European CSCs. Determining such a threshold will nevertheless be a difficult exercise, and could be based on a number of plants or specific quantity (in grams) per month/year. The Belgian experience which is based on one plant per member (mainly due to the clubs' interpretation of prosecution guidelines applicable in that country) or the limit of $40 \mathrm{~g}$ per month set out by the Uruguayan legislation could be useful starting points for thinking about such thresholds. Production limits, corresponding to the quantity thresholds mentioned above may also be introduced. At the moment, only Uruguay has introduced a concrete limit for production, which is set at 99 plants (at one given time). In Belgium, the total number of plants corresponds to the total number of members (as clubs report cultivating one plant per member).

Additionally, decisions about the number of cultivation sites authorised per club and the size of each of those cultivation sites should also be considered. While the practices in the three countries have shown that the clubs draft agreements with their growers (in Belgium) or have to prepare a crop plan (in Uruguay), the relations between clubs and growers have at times been troublesome.

CSC members often see high product quality, purity and control of content among the biggest benefits the CSCs provide (Belackova et al., 2016). However, we found no unified system of quality control in place in any of the three countries. The monitoring of cultivation practices remains a point for attention, even in the case of Uruguay, where regulation applicable to the model has been introduced. An important obstacle to implement standardised toxicological analyses to ensure the quality, potency and purity of cannabis supplied by the clubs, would be its considerable cost (see also: Belackova et al., 2016) and the current domestic legal frameworks.

Our analysis has also uncovered a number of different modes of distribution of cannabis adopted by the clubs. In some cases, the cannabis is distributed to the members in bulk, for instance after harvest (see for instance the 'exchange fairs' organised by some Belgian CSCs, or monthly deliveries by Uruguayan CSCs). In other instances clubs accept on demand orders, and finally other clubs have a permanent stock of cannabis and allow members to collect their desired amount during the opening hours of the club, without the need for any prior notice (this is the standard practice by Spanish clubs). Whether and how these modes affect the consumption levels of the cannabis users members of the clubs remains to be further assessed.

\section{Conclusions}

This paper identifies the ways in which the CSC model has developed in three different contexts, under different domestic legal frameworks. As discussed throughout, many similarities and differences in terms of the practices of the CSCs within and across countries emerged (Pardo, 2014). Understanding these aspects provides important pointers which could inform potential future regulation in this field. In our view, such a regulatory framework will need to strike a balance between sufficiently allowing and accommodating the self-regulatory efforts of those involved in the CSC model to date, but at the same time ensuring adequate governmental control with a view to protecting and promoting public health goals. As the CSC movement expands, sole reliance on self-regulatory practices and a non-profit ethos becomes, in our view, difficult without more formal controls - a lesson learnt from the Spanish experience, where some large, commercial CSCs have emerged, despite the presence of CSC federations. A legal framework complementing self-regulatory efforts may help prevent CSCs from morphing into profit-driven organisations and the emergence of 'shadow clubs' which seek to produce and distribute cannabis in a commercial way (Bewley-Taylor et al., 2014; Decorte, 2015). Such regulatory model could remove incentives for profit-motivated efforts by clubs to increase cannabis consumption by banning any advertising and marketing practices by clubs (such as on pack branding) - which seems to already be the case in the contexts studied herein; and again, by imposing a maximum number of members and a maximum production limit (monthly/annually). Keeping in line with public health objectives, access, availability and use by youths should also be minimised (Pacula et al., 2014; Kilmer, 2014).

At the same time, CSCs could retain their current autonomy to shape the decision-making structure of the club, make decisions on membership fees, the choice to hire paid staff, the planning of cannabis production, the selection of strains to be produced, or the decision to form a federation with other clubs. At the same time, legal regulation could define the procedure for formal registration and establishment of the club, establish a maximum number of members per CSC, the club's maximum production capacity (in $\mathrm{kg}$ ? number of plants?), the maximum number of grams a member can receive in a given period, the minimum membership criteria (such as age and a residence criterion), and procedures to ensure transparency of the activities and the finances of the clubs (e.g. a crop plan as required in Uruguay, or external accountability checks). With regards to the registration of cannabis users, other experiments imposing a registration system - such as the implementation of the 'weed pass' for coffeeshops in The Netherlands, seem to suggest that many users are reluctant to formally complete such registration. Current experiences in Uruguay (where a users' registry has also been introduced) can further shed light into this issue.

Belackova et al. (2016) have argued that the Cannabis Social Club model has the potential to diminish the adverse health risks resulting from cannabis use through educational activities, dissemination of information on reducing mental health risks, and promotion of safe smoking practices. However, there may be risks associated with sole reliance on self-regulatory practices of CSCs, given the inherent potential conflict of interest between profit-making (which is the goal of at least some groups and individuals in the CSC movement) and accountability (as a crucial element in the 'Code of Conduct') (see: Ritter, 2010). Similarly, Pacula et al. (2014) have warned for a laissez-faire approach, which could generate an increase in cannabis misuse and consequent health and social problems. In order to protect and ensure public health, a regulatory framework could contain minimal quality standards for growing cannabis within a club, establish a 
maximum THC-content (and a minimum of CBD and CBN content?) of cannabis products, packaging controls (e.g. childproof containers) and obligatory information on packaging (based on established norms for pharmaceutical drugs, and also containing information about responsible cannabis use, how to minimize risks, and where to find more information or help).

Unlike cannabis distributors who operate on the illegal market, many Cannabis Social Clubs are willing to enter into dialogue with authorities to provide insight in their working methods, in the framework of the elaboration of a legal regulation of cannabis. Public health regulations would enable authorities to control the CSCs in order to ensure their transparent and safe way of working, and to create an alternative for the black market, preventing the access of minors to cannabis, help to reduce public expenditure and generate tax revenue (see also: Pacula et al., 2014). Public health regulations could also enable the clubs to apply an active policy of prevention of harms and risks, and to actively promote safer methods of consumption of cannabis (Ritter, 2010). Any experiment with regulated Cannabis Social Clubs should also be tailored to the local context. This implies a discussion about the location and density of clubs per area (a point taken up in Uruguayan legislation), about whether or not it is good practice to allow consumption of cannabis (and/or alcohol) at the venue of the clubs, and about the distribution procedures (during opening hours, by order only, through frequent 'distribution fairs', etc.).

CSCs too have an interest in such a regulation as it will ensure legal availability of cannabis to their members, their right to freedom of peaceful assembly and association, and the legal status of their organisation and activities.

The study presented here obviously has important limitations: the data used for this analysis were not collected through identical data collection methods, and stem from local studies in Spain, Belgium and Uruguay with different research designs. Some of the issues we mentioned above require more in-depth descriptions of how CSCs operate on a daily basis. Not all the CSCs in the three countries were included in our studies; some clubs are of difficult access or reluctant to participate in empirical research, and it is well worth trying to find out why. In order to better understand the strengths and the weaknesses of the CSC model and the lessons for regulation, analysis of the sociodemographic background, and consumption patterns of CSC members (before and during CSC membership) would be very useful, as well as their personal views and experiences with (one or more) clubs. Furthermore, it seems important to know which 'type' of cannabis users clubs are attracting today (regular or daily cannabis users, and/or irregular and occasional users) and to reflect on how legally regulated cannabis clubs should target different groups of cannabis users. Similarly, a better knowledge of the background of current cannabis growers in CSCs would be of added value, as any transition from a criminalised to a legally regulated framework will raise important issues with regards to the previous illicit cannabis growers.

\section{Acknowledgements}

The authors would like to thank the representatives of the Cannabis Social Clubs in Spain, Belgium and Uruguay who participated in the local studies. The ongoing Belgian study is funded through the Research Foundation - Flanders (FWO) (grant no. G.0A85.15N). The Spanish co-authors would like to thank the two Catalan Federations of Cannabis Associations: Federació d'Associacions de Cànnabis de Catalunya (FEDCAC) and Federació d'Associacions Cannàbiques Autoregulades de Catalunya (CATFAC) for providing useful data for this paper. The Uruguayan co-authors would like to thank Universidad Católica del Uruguay and the Open Society Foundations for funding their project on cannabis clubs in
Uruguay. Alejandra Triñanes, Mauricio Coitiño, and Macarena López worked as research assistants for this project, we thank them for their dedication and insights.

\section{Conflict of interest statement}

We wish to confirm that there are no known conflicts of interest associated with this publication.

\section{References}

Arana, X. (2013). Código de Buenas Prácticas de los Clubes Sociales de Cannabis. Universidad del País Vasco: Instituto Vasco de Criminología.

Barriuso, M. (2005). Propuesta de modelo legal para el cannabis en el estado espanol. Revista del Instituto Vasco de Criminologia, 19, 151-167.

Barriuso, M. (2011). Cannabis Social Clubs in Spain: A normalizing alternative underway. Series on Legislative Reform of Drug Policies, 9, 1-8.

Belackova, V., Tomkova, A., \& Zabransky, T. (2016). Qualitative research in Spanish Cannabis Social Clubs: 'The Moment You Enter the Door, You Are Minimising the Risks'. International Journal of Drug Policy, 34, 49-57.

Bewley-Taylor, D., Blickman, T., \& Jelsma, M. (2014). The rise and decline of cannabis prohibition. The history of cannabis in the UN drug control system and options for reform. Amsterdam: Transnational Institute and Global Drug Policy Observatory.

Boidi, M. F, Queirolo, R. \& Cruz, M. (2015). Marijuana consumption patterns among frequent consumers in Montevideo. Paper presented at the 9th conference of the International Society for the Study of Drug Policy (ISSDP) (pp. 2015.

CATFAC (2014). Codi de Bones Pràctiques per a les Associacions Cannàbiques. CATFAC. Caulkins, J. P., Kilmer, B., Kleiman, M. A. R., MacCoun, R. J., Midgette, G., Oglesby, P., et al. (2015). Considering marijuana legalization: Insights for Vermont and other jurisdictions. Santa Monica: RAND Corporation.

Caulkins, J. P., Kilmer, B., Kleiman, M. A. R., MacCoun, R. J., Midgette, G., Oglesby, P., et al. (2015). Options and issues regarding marijuana legalization. Santa Monica: RAND Corporation.

Decorte, T. (2015). Cannabis Social Clubs in Belgium: Organizational strengths and weaknesses, and threats to the model. International Journal of Drug Policy, 26, 122-130.

Decorte, T., De Grauwe, P., \& Tytgat, J. (2013). Cannabis: Bis? Pleidooi voor een kritische evaluatie van het Belgische cannabisbeleid. Leuven: KU Leuven \& Universiteit Gent.

Decorte, T., Paoli, L., Kersten, L., Heyde, J., Van Dun, E., \& Vlaemynck, M. (2014). Cannabis production in Belgium: Assessment of the nature and harms, and implications for priority setting. Gent: Academia Press.

Díez, J. L., \& Muñoz, J. (2012). Dictamen sobre la viabilidad legal de los clubes sociales de cannabis, como modelo de autoorganización del consumo. Revista de Jueces para la Democracia, 75(November).

EMCDDA (2015). European legal database on drugs. EMCDDA from http://www. emcdda.europa.eu/eldd. (Retrieved 16 October 2015).

European Coalition for Just and Effective Drug Policies (ENCOD). (2011). from http:// www.encod.org/info/CODE-OF-CONDUCT-FOR-EUROPEAN.html. (Retrieved 13 December 2016).

FEDCAC (2013). Codi de bones pràctiques per a les associacions cannàbiques. FEDCAC.

García, F.Á., \& Manjón-Cabeza, A. (2009). El delito de tráfico de drogas. Valencia: Tirant Lo Blanch.

Gelders, D., \& Vander Laenen, F. (2007). 'Mr Police Officer, I thought cannabis was legal'-Introducing new policy regarding cannabis in Belgium: A story of good intentions and Babel. Drugs: Education, Prevention and Policy, 14(2), 103-116.

Generalitat de Catalunya Departament de Salut. (2015). Resolució SLT/32/2015, de 15 de gener, per la qual s'aproven criteris en matèria de salut pu'blica per orientar les associacions cannàbiques $i$ els seus clubs socials $i$ les condicions de l'exercici de la seva activitat per als ajuntaments de Catalunya. núm. 6799. 29.1.2015. from http://www.observatoriocivil.org (Retrieved 15 April 2016).

IACM. (2016). Medical uses. from http://cannabis-med.org/index.php?tpl=page\&id=21\&lng=en\&sid=987970405933d0358a1a8fac8e46ea5f. (Retrieved 1 February 2016).

IRCCA (2014). Condiciones para la habilitación de los clubes de membresia. Funcionamiento, infraestructura y seguridad. Montevideo: IRCCA.

Kilmer, B. (2014). Policy designs for cannabis legalization: Starting with the eight Ps. American Journal of Drug and Alcohol Abuse, 40(4), 259-261.

Kilmer, B., Kruithof, K., Pardal, M., Caulkins, J. P., \& Rubin, J. (2013). Multinational overview of cannabis production regimes. Santa Monica: RAND Corporation.

Korf, D. (2011). Marihuana behind and beyond coffee shops. In T. Decorte, G. Potter, \& M. Bouchard (Eds.), World wide weed. Global trends in cannabis cultivation and its control (pp. 181-193).Surrey: Ashgate Publishing Company.

MacCoun, R. (2013). The paths not (yet) taken: Lower risk alternatives to full-market legalization of cannabis. In K. Tate, J. L. Taylor, \& M. Q. Sawyer (Eds.), Something's in the air: race, crime, and the legalization of marijuana (pp. 40-53).New York: Routledge.

MacCoun, R., Reuter, P., \& Schelling, T. (1996). Assessing alternative drug control regimes. Journal of Policy Analysis and Management, 15(3), 330-352.

MacCoun, R. J., \& Reuter, P. (2011). Assessing drug prohibition and its alternatives: A guide for agnostics. In J. Hagan, K. L. Scheppele, \& T. R. Tyler (Eds.), Annual review of law and social science: (Vol. 7. pp. 61-78). 
Manzanera, R., Torralba, L., Brugal, M., Armengol, R., Solanes, P., \& Villalbí, J. R. (2000). Afrontar los estragos de la heroína: Evaluación de diez años de un programa integral en Barcelona. Gaceta Sanitaria, 14(1), 58-66.

Marín, I. (2008). La Cultura Cannabica en Espana (1991-2007). Analisis Socioantropologico de un Nuevo Tipo de Movimiento Social. Universidad de Granada.

Montañés, V. (2014). Rompiendo el hielo: La regulacion del cannabis en Paises Bajos, Colorado y Uruguay. San Sebastian: Fundacion Renovatio.

Mumbrú, J. (2015, 20 March 2015). Las entidades cannábicas presentan una ILP para forzar la regulación. El Pais. Retrieved from http://ccaa.elpais.com/ccaa/2015/ 03/20/catalunya/1426882323_369590.html.

Munoz Sánchez, J. (2015). La relevancia penal de los clubes sociales de cannabis: Reflexiones sobre la politica de cannabis y anålisis jurisprudencial. Revista Electronica de Ciencia Penal y Criminologia (on linea)1-50 nu'm. 17-22 p. 16.

Pacula, R. L., Kilmer, B., Wagenaar, A. C., Chaloupka, F. J., \& Caulkins, J. P. (2014). Developing public health regulations for marijuana: Lessons from alcohol and tobacco. American Journal of Public Health, 104(6), 1021-1028.

Pardal, M. (2016) Cannabis Social Clubs through the lens of the drug user movement. Tijdschrift over Cultuur \& Criminaliteit, (6),2, 47-58

Pardal (forthcoming). Cannabis Social Clubs in Belgium: a study of the organization of collective cannabis cultivation for personal use and characteristics of club members. Available at: http://www.ugent.be/re/cssr/en/research-groups/isd/ projects.htm/cannabissocialclubsbelgiumfwo.htm (Accessed February 2017)

Pardo, B. (2014). Cannabis policy reforms in the Americas: A comparative analysis of Colorado, Washington, and Uruguay. International Journal of Drug Policy, 25, 727-735.

Parés, Ò., \& Bouso, J. C. (2015). Innovation born of necessity. Pioneering drug policy in Catalonia. New York: Open Society Foundations.
Parlamento de Navarra (2014). Ley Foral reguladora de los clubes sociales de cannabis en Navarra. Parlamento de Navarra.

Parlamento Vasco. (2014). Informe de la ponencia para el análisis de una solución regulada de la actividad de los denominados clubes sociales de cannabis. Resolución conjunta PNV, PSE y Bildu. (numéro expidiente: $10|11 \backslash 08| 00 \mid 0004), 14.11 .2014$, nr. 102, p. 18723).

Queirolo, R., Boidi, M. F., \& Cruz, J. M. (2016). Cannabis Clubs in Uruguay: The challenges of regulation. International Journal of Drug Policy, 34, 41-48.

Reyero I., \& Carra A. (2014, 11 December 2014). El Gobierno recurre la ordenanza de San Sebastián para legalizar clubes de cannabis. $A B C$. Retrieved from http:// www.abc.es/sociedad/20141211/abci-cannabis-club-sansebastian-gobierno201412111817.html.

Ritter, A. (2010). Illicit drugs policy through the lens of regulation. International Journal of Drug Policy, 21, 265-270.

Room, R., Fischer, B., Hall, W., Lenton, S., \& Reuter, P. (2010). Cannabis policy. Moving beyond stalemate. New York: Oxford University Press.

Transform (2013). How to regulate cannabis: A practical guide. Transform Drug Policy Foundation.

X. (2014, 2 January 2014). Cultivadores de cannabis crearon federación para incidir en política. El Observador. Retrieved from http://www.elobservador.com.uy/ cultivadores-cannabis-crearon-federacion-incidir-politica-n268730.

X. (2015, 18 April 2015). El Gobierno central ve inconstitucional la ley vasca de adicciones por legalizar "de hecho» el cannabis. El Diario Vasco. Retrieved from http://www.diariovasco.com/sociedad/201504/18/gobierno-central-inconstitucional-vasca-20150418133350.html. 